\title{
A novel pyruvate kinase and its application in lactic acid production under oxygen deprivation in Corynebacterium glutamicum

\author{
Xin Chai ${ }^{1,2}$, Xiuling Shang ${ }^{1}$, Yu Zhang ${ }^{1,2}$, Shuwen Liu', Yong Liang ${ }^{1}$, Yun Zhang ${ }^{1 *}$ and Tingyi Wen ${ }^{1,3^{*}}$
}

\begin{abstract}
Background: Pyruvate kinase (Pyk) catalyzes the generation of pyruvate and ATP in glycolysis and functions as a key switch in the regulation of carbon flux distribution. Both the substrates and products of Pyk are involved in the tricarboxylic acid cycle, anaplerosis and energy anabolism, which places Pyk at a primary metabolic intersection. Pyks are highly conserved in most bacteria and lower eukaryotes. Corynebacterium glutamicum is an industrial workhorse for the production of various amino acids and organic acids. Although C. glutamicum was assumed to possess only one Pyk (pyk1, NCgl2008), NCgl2809 was annotated as a pyruvate kinase with an unknown role.

Results: Here, we identified that NCgl2809 was a novel pyruvate kinase (pyk2) in C. glutamicum. Complementation of the WT $\Delta p y k 1 \Delta p y k 2$ strain with the pyk2 gene restored its growth on D-ribose, which demonstrated that Pyk2 could substitute for Pyk1 in vivo. Pyk2 was co-dependent on $\mathrm{Mn}^{2+}$ and $\mathrm{K}^{+}$and had a higher affinity for ADP than phosphoenolpyruvate (PEP). The catalytic activity of Pyk2 was allosterically regulated by fructose 1,6-bisphosphate (FBP) activation and ATP inhibition. Furthermore, pyk2 and IdhA, which encodes L-lactate dehydrogenase, were cotranscribed as a bicistronic mRNA under aerobic conditions and pyk2 deficiency had a slight effect on the intracellular activity of Pyk. However, the mRNA level of pyk2 in the wild-type strain under oxygen deprivation was 14.24-fold higher than that under aerobic conditions. Under oxygen deprivation, pyk1 or pyk2 deficiency decreased the generation of lactic acid, and the overexpression of either pyk 1 or pyk2 increased the production of lactic acid as the activity of Pyk increased. Fed-batch fermentation of the pyk2-overexpressing WT $\Delta$ pyk1 strain produced 60.27 $\pm 1.40 \mathrm{~g} / \mathrm{L}$ of lactic acid, which was a $47 \%$ increase compared to the parent strain under oxygen deprivation.
\end{abstract}

Conclusions: Pyk2 functioned as a pyruvate kinase and contributed to the increased level of Pyk activity under oxygen deprivation.

Keywords: Corynebacterium glutamicum, Pyruvate kinase, Oxygen deprivation, Lactate dehydrogenase, Fructose 1,6bisphosphate

\section{Background}

Pyruvate kinase catalyzes the transphosphorylation from PEP to ADP to generate pyruvate and ATP in glycolysis [1]. Pyks are highly conserved in both eukaryotes and prokaryotes [2, 3]. In mammals, four types of Pyk isoenzymes (M1, M2, L and R) with different kinetic properties are distributed in various tissues to satisfy the diverse metabolic requirements. Most bacteria and lower

\footnotetext{
* Correspondence: zhangyun@im.ac.cn; wenty@im.ac.cn

${ }^{1}$ CAS Key Laboratory of Pathogenic Microbiology and Immunology, Institute of Microbiology, Chinese Academy of Sciences, Beijing 100101, People's Republic of China

Full list of author information is available at the end of the article
}

eukaryotes have only one form of Pyk. However, there are two identified Pyk isoenzymes in Escherichia coli, Salmonella typhimurium and Saccharomyces cerevisiae. The activities of Pyks are dependent on a bivalent and/ or a univalent cation $\left(\mathrm{Mn}^{2+} / \mathrm{Mg}^{2+}\right.$ and/or $\left.\mathrm{K}^{+}\right)$[1]. In the majority of organisms, Pyk is a homotetramer that exhibits inactive/active reversible allosteric mechanisms [4]. The functional forms of Pyks are divided into the following two broad types based on their allosteric effectors: type I is allosterically activated by FBP, whereas type II is allosterically activated by AMP and monophosphorylated sugars [1]. The allosteric behavior of Pyk allows it to be an important switch point for the regulation of carbon flux distribution. 
The two most studied allosteric Pyk isoenzymes are those of E. coli and S. cerevisiae. In E. coli, PykF exhibited higher activity than PykA in vitro, and PykF and PykA played different roles in pyruvate synthesis and cell growth [5-7]. In S. cerevisiae, FBP-activated Pyk1p was the major enzyme that catalyzed the conversion of PEP to pyruvate, whereas Pyk $2 p$ with relatively low enzymatic activity was insensitive to FBP and subject to glucose repression, which suggested that Pyk $2 p$ played a major role under conditions of low glycolytic flux [8]. To date, little is known about other Pyk isoenzymes and their physiological function in other bacteria.

Corynebacterium glutamicum is widely used for the industrial production of various amino acids and vitamins during aerobic cultivation due to the robustness of its genetic modifications and fermentation [9]. Under oxygen deprivation, C. glutamicum can primarily convert glucose to pyruvate, which is an intermediate for the production of organic acids and amino acids despite the cessation of growth [10-13]. Two genes [NCgl2008 (pyk1) and $N C g l 2809$ (pyk2)] were annotated as pyruvate kinases in the genome of C. glutamicum ATCC 13032 [9]. The deletion of pyk1 resulted in marginal Pyk activity that was below the detection limit, which supported the assertion that C. glutamicum possessed only one pyruvate kinase $[14,15]$. Pyk1 exhibited high catalytic activity using $\mathrm{Mn}^{2+}$ or $\mathrm{Co}^{2+}$ as a cation and subjected to AMP activation and ATP inhibition [16]. The expression of $p y k 1$ was repressed by the global transcriptional regulator SugR, which binds to the promoters of many target genes involved in glycolysis (i.e., gapA, pfkA, fba, eno, pyk 1 and $l d h A$ ) to regulate sugar metabolism $[17,18]$. The deletion of $p y k 1$ led to decrease biomass and increase glutamic acid production [14]. Therefore, Pyk1 functioned as an effective metabolic engineering node for the production of various metabolites [19]. The genetic organization of the homologous pyk2, which is adjacent to $l d h A$, exists in many Corynebacterium species. However, the function and biological significance of Pyk2 has not been understood.

In this study, we identified NCgl2809 (Pyk2) as a functional pyruvate kinase in C. glutamicum. Pyk2 exhibited different enzymatic properties compared to Pyk1 and could substitute for Pyk1 in vivo. Under oxygen deprivation, $p y k 1$ or $p y k 2$ deficiency decreased the generation of lactic acid, and the overexpression of either $p y k 1$ or $p y k 2$ increased the production of lactic acid.

\section{Results}

\section{Pyk2 is a pyruvate kinase in C. glutamicum}

NCgl2809 was annotated as a pyruvate kinase in the genome of C. glutamicum ATCC 13032 (WT). This gene is adjacent to $l d h A$ and distant from $p y k 1$ (Additional file 1: Figure S1a). A protein homology search and alignment indicated that Pyk2 had moderate sequence identity to the functionally identified Pyk1 of C. glutamicum (32\%), PykF of E. coli (30\%) and PykA of E. coli (27\%), but showed high sequence identity to the annotated homologs from other species of Corynebacterium. Using the PykF crystal structure from E. coli (PDB code $1 \mathrm{PKY}$ ) as a template, the secondary structure of Pyk2, which ranged from 128 to 213 residues and 346 to 606 residues, consisted of $12 \alpha$-helices and $16 \beta$-strands structures. This structure was similar to the catalytic domain A of PykF (Additional file 1: Figure S1b and c), in which the GDLGVE motif served as the PEP binding site and the conserved sequences assisted the FBP allosteric regulation. A long extra $\mathrm{N}$-terminal sequence of 120 amino acids made Pyk2 (67.6 kDa) larger than other typical bacterial Pyks $(51 \mathrm{kDa})$.

To demonstrate the function of Pyk2 in vivo, the pyk2 and/or pyk1 genes were deleted in the chromosome. The WT $\Delta p y k 1 \Delta p y k 2$ strain grown on glucose under aerobic conditions exhibited only a slightly lower growth rate than the WT strain $(P<0.05)$, which indicated that the conversion of PEP to pyruvate during glucose transport by the phosphotransferase transport system (PTS) could supply pyruvate for cell growth (Additional file 1: Table S1). To eliminate the effect of the pyruvate generated from the glucose transport on growth, D-ribose, which was imported by the ribose-specific ATP-binding cassette transport system, was employed as the sole carbon source to evaluate the role of Pyk isoenzymes under aerobic conditions [20]. As shown in Fig. 1a, the WT $\Delta p y k 2$ strain showed similar growth compared to the WT strain. However, the WT $\Delta p y k 1$ strain showed a $52 \%$ decrease in the final biomass and the WT $\Delta p y k 1 \Delta p y k 2$ strain failed to grow when D-ribose was the sole carbon source, which suggested that the $p y k 2$ gene maintained cell growth on D-ribose to some extent. Moreover, complementation of the WT $\Delta p y k 1$ strain with the pyk2 gene restored its growth in the same manner as the pyk1 gene (Fig. 1b), which indicated that Pyk2 could substitute for Pyk1 in C. glutamicum. Furthermore, complementation of the WT $\Delta p y k 1 \Delta p y k 2$ strain with $p y k 1$ and pyk 2 completely restored its growth (Fig. 1c). In addition, the overexpression of $p y k 2$ in the WT $\Delta p y k 1 \Delta p y k 2$ strain made the specific activities of Pyk $(448.81 \pm 19.25 \mathrm{mU} / \mathrm{mg})$ comparable to that of overexpression of pyk1 (458.76 \pm $7.99 \mathrm{mU} / \mathrm{mg}$ ) in the WT $\Delta p y k 1 \Delta p y k 2$ strain. Altogether, our results strongly supported that Pyk2 functioned as a pyruvate kinase in vivo.

\section{Enzymatic properties of Pyk2}

To detect the activity of Pyk2 in vitro, the pyk2 gene of $C$. glutamicum was expressed in E. coli BL21 (DE3) using the pET-28a expression system. N-terminal His-tagged Pyk2 exhibited similar activity to Pyk2 with the His-tag removed by thrombin cleavage. After further purification using ion exchange chromatography, the recombinant Pyk2 showed 

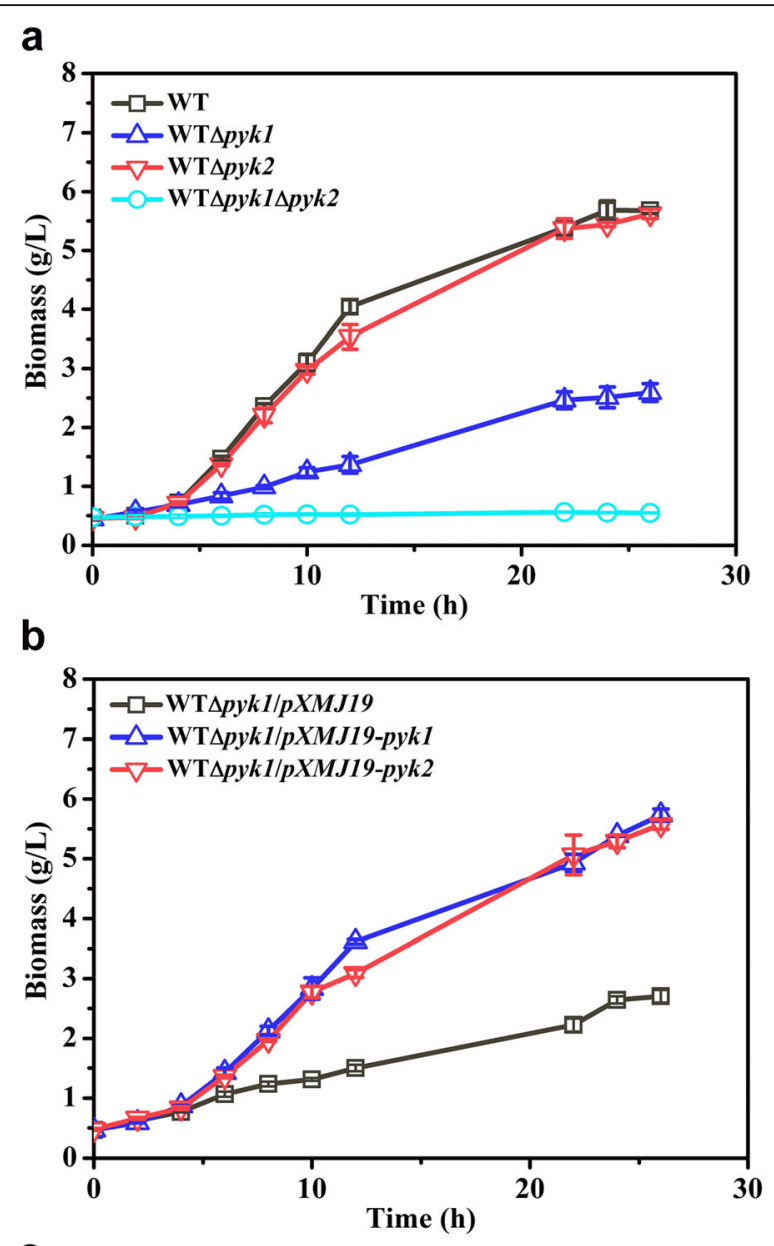

C

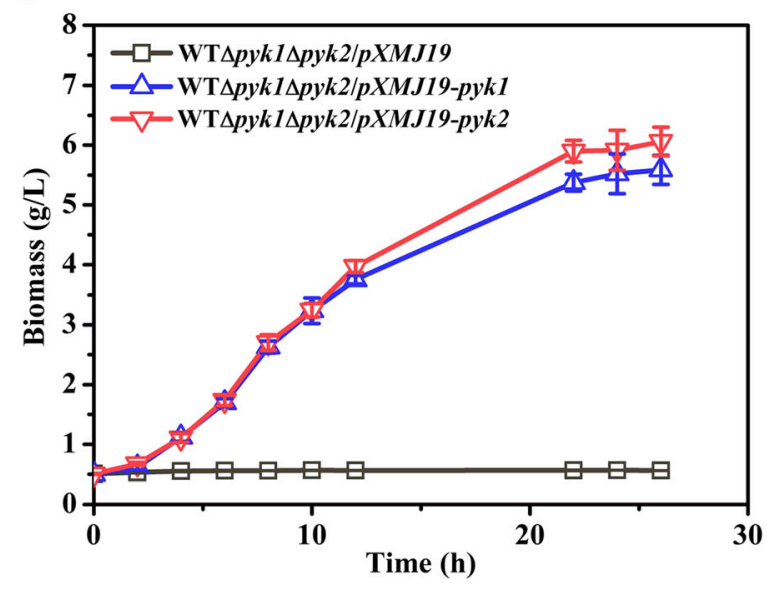

an approximately 12.81 -fold purification with a yield of $37 \%$ and a specific activity of $1.64 \mathrm{U} / \mathrm{mg}$. The molecular weight of the recombinant Pyk2 subunit was 67,572 Da (Fig. 2a). Gel filtration chromatography yielded a 430,881 Da fraction that corresponded to the predicted size of a homohexamer,
Fig. 1 Growth of C. glutamicum strains on CGXII medium with $100 \mathrm{mM}$ D-ribose under aerobic conditions. C. glutamicum strains were aerobically pre-cultivated in $50 \mathrm{~mL}$ of CGIII medium. After washing the cells in CGXII minimal medium, the cultures were inoculated to obtain optical densities at $600 \mathrm{~nm}$ of approximately 1.5 (dry cell weight of $0.45 \mathrm{~g} / \mathrm{L}$ ). When necessary, $0.5 \mathrm{mM}$ IPTG was supplemented after inoculation. a WT, WT $\Delta p y k 1$, WT $\Delta p y k 2$ and WT $\Delta$ pyk1 1 pyk2. b WT $\Delta p y k 1 / p X M J 19$,

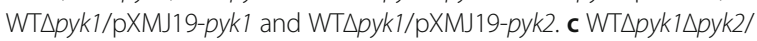
pXMJ19, WT $\Delta p y k 1 \Delta p y k 2 / p X M J 19-p y k 1$ and WT $\Delta p y k 1 \Delta p y k 2 / p X M J 19-$ pyk2. The data were derived from experiments performed at least in three times, and the error bars represent the standard deviations

which was different from the homotetramer observed for other Pyks (Fig. 2b).

Pyk2 was active at temperatures between 20 and $50{ }^{\circ} \mathrm{C}$, with a maximal activity at $35{ }^{\circ} \mathrm{C}$ (Fig. 2c). The enzyme maintained greater than $80 \%$ of its relative activity at a $\mathrm{pH}$ range between 6 and 9, with a maximal activity at $\mathrm{pH} 7.0$ (Fig. 2d). Pyk2 exhibited an absolute dependence on $\mathrm{Mn}^{2+}$ together with a monovalent cation. This finding was quite different from Pyk1 in C. glutamicum, which only used $\mathrm{Mn}^{2+}$ or $\mathrm{Co}^{2+}$ as cations [16]. Among all the tested monovalent cations, the maximum activity of Pyk2 was detected in the presence of $5 \mathrm{mM} \mathrm{Mn}^{2+}$ and $100 \mathrm{mM} \mathrm{K}^{+}$. When $\mathrm{NH}_{4}^{+}, \mathrm{Na}^{+}$, or $\mathrm{Li}^{+}$was substituted for $\mathrm{K}^{+}$, the relative activities of Pyk2 were maintained at 73,51 , and $38 \%$, respectively (Fig. 2e).

\section{Kinetic parameters of Pyk2}

The kinetics of Pyk2 were determined with respect to PEP and ADP as described in the Methods section (Fig. 3 and Additional file 1: Table S2). As shown in Table S2, the $S_{0.5}$ value of Pyk2 for PEP was $4.58 \pm 0.74 \mathrm{mM}$, and the $k_{\text {cat }}$ value was $5.58 \pm 0.53 \mathrm{~s}^{-1}$, which was lower than that of Pyk1 [16]. The $k_{\text {cat }}$ value of Pyk2 for ADP was $4.36 \pm$ $0.22 \mathrm{~s}^{-1}$, and the $S_{0.5}$ value was $0.33 \pm 0.03 \mathrm{mM}$ (Fig. $3 \mathrm{~b}$ ); this latter value was 4.71-fold higher than that of C. glutamicum Pyk1 (0.07 mM), which indicated that Pyk2 had a relatively lower affinity for ADP compared to Pyk1.

The kinetic properties of Pyk2 in response to different effectors were determined to understand its allosteric regulation. In the presence of $5 \mathrm{mM}$ FBP (Fig. 3c), the $S_{0.5}$ of Pyk2 for PEP was dramatically decreased to $2.17 \pm$ $0.12 \mathrm{mM}$ and the $k_{\text {cat }}$ value was increased to $7.67 \pm 0.26 \mathrm{~s}^{-1}$, which demonstrated that Pyk2 was dependent on FBP activation. However, glucose-6-phosphate (G6P) had no significant effect on the $S_{0.5}$ and $k_{\text {cat }}$ of Pyk2 (Additional file 1: Figure S2a). In addition, there was no significant effect of AMP on the $S_{0.5}$ and $k_{\text {cat }}$ of Pyk2 (Additional file 1: Figure $\mathrm{S} 2 \mathrm{~b})$. The kinetic properties of Pyk2 were similar to E. coli PykF and different from C. glutamicum Pyk1, which was activated by AMP [1]. Moreover, ATP had an inhibitory effect on Pyk2 because the $k_{\text {cat }}$ for PEP decreased to $2.09 \pm$ $0.10 \mathrm{~s}^{-1}$ (Fig. 3d). In addition, in the presence of citrate (CIT), the sigmoidal nature of the activity curve increased 

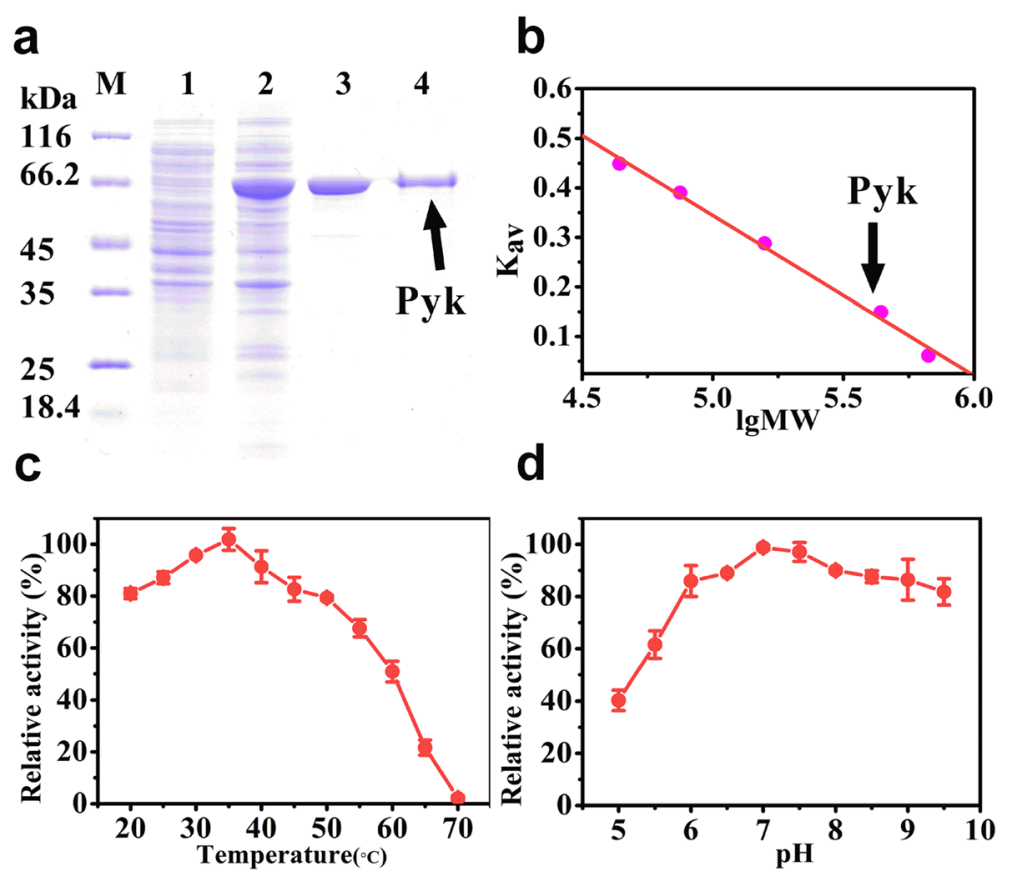

e

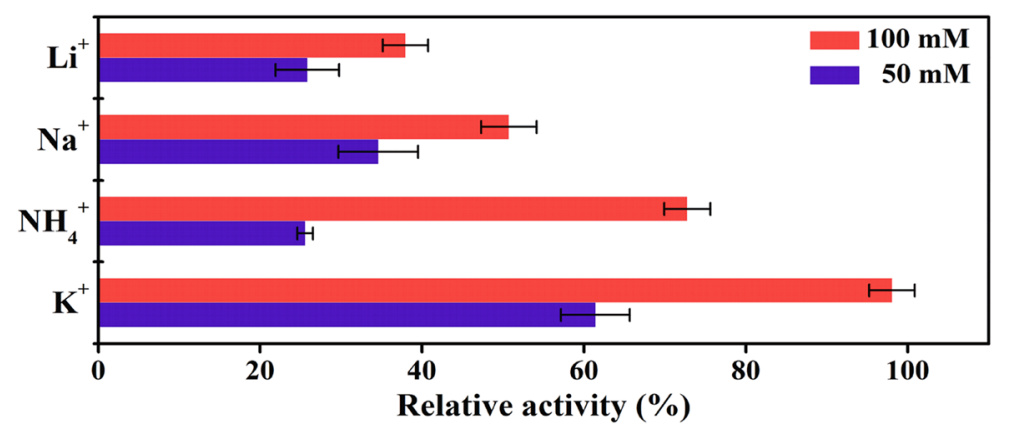

Fig. 2 Enzymatic properties of Pyk2 from C. glutamicum. a SDS-PAGE of purified Pyk2. Lane 1, supernatant of crude extract from E. coli BL21(DE3)/ pET-28a; Lane 2, supernatant of crude extract from E. coli BL21(DE3)/pET-28a-pyk2; Lane 3, Pyk2 purified by His-tagged affinity chromatography; and Lane 4, Pyk2 purified by ion exchange chromatography. $\mathbf{b}$ Molecular weight determination by gel filtration chromatography. The molecular weight of a protein could be determined from the calibration curve (plot of $K_{a v}$ versus the logarithm of molecular weight). The $K_{a v}$ value was calculated from the measured elution volume using the following equation: $\left.K_{a v}=\left(V_{e}-V_{0}\right) / V_{c}-V_{0}\right)$, where $V_{e}$ is the elution volume, $V_{0}$ is the column void volume, and $V_{c}$ is the geometric column volume. The logarithm of the molecular weight was represented as lgMW. The standard proteins were shown as follows (•): 1, ovalbumin (44 kDa); 2, conalbumin (75 kDa); 3, aldolase (158 kDa); 4, ferritin (440 kDa); and 5, thyroglobulin (669 kDa). The native molecular weight of Pyk2 was determined to be a homohexamer of 430,881 (arrow). c The enzyme activity of Pyk2 at different temperatures. The maximum value of 2.19 $\pm 0.09 \mathrm{U} / \mathrm{mg}$ was set as relative $100 \%$. $\mathbf{d}$ Enzyme activities of Pyk2 at various $\mathrm{pHs}$ (The maximum value of $2.43 \pm 0.02 \mathrm{U} / \mathrm{mg}$ was set as relative $100 \%$ ). e Enzyme activities of Pyk 2 in the presence of various monovalent ions (The maximum value of $1.77 \pm 0.05 \mathrm{U} / \mathrm{mg}$ was set as relative $100 \%$ ). The enzyme was incubated in $100 \mathrm{mM}$ Tris-HCl buffer ( $\mathrm{pH}$ 7.4) and $5 \mathrm{mM} \mathrm{Mn}^{2+}$ with $50 \mathrm{mM}$ or $100 \mathrm{mM}$ monovalent ions. The data were derived from at least three replicate experiments, and the error bars represent the standard deviations

to a Hill coefficient of 3.66 that was indicative of increased cooperativity (Fig. 3e). Altogether, the FBP-activated Pyk2 was different from the AMP-activated C. glutamicum Pyk1.

\section{The expression of pyk 2 is induced under oxygen deprivation}

Considering that the transcriptional direction of $p y k 2$ and the neighboring $l d h A$ genes in the chromosome are similar, RT-PCR was performed using two primers designed against the overlapping adjacent region of the two genes to determine whether $p y k 2$ and $l d h A$ were co-transcribed. Under aerobic conditions, a single 491 bp PCR product was obtained, which indicated that $p y k 2$ and $l d h A$ were co-transcribed as a bicistronic mRNA (Fig. 4a). The expression levels of $p y k 1, p y k 2$ and $l d h A$ in the WT strain were then further investigated using qRT-PCR under aerobic and oxygen-deprived conditions. The mRNA level of pyk2 under oxygen deprivation was 14.24-fold higher than 
a
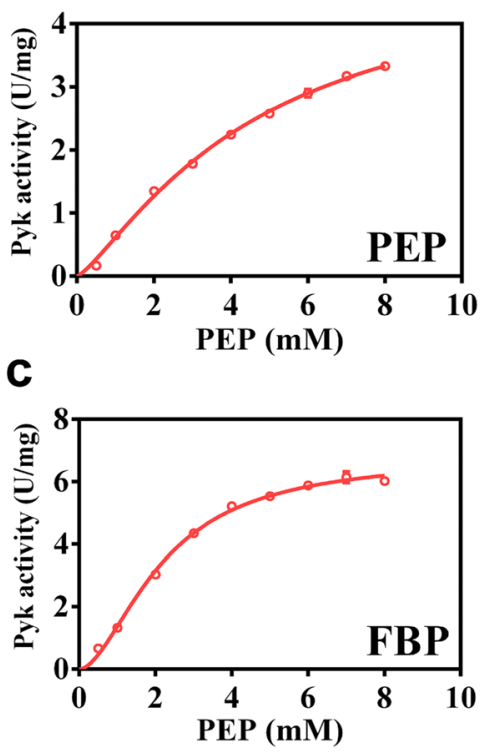

e

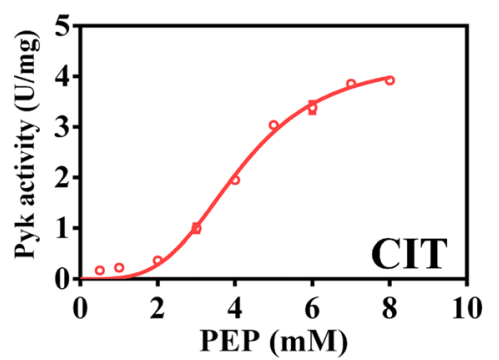

b
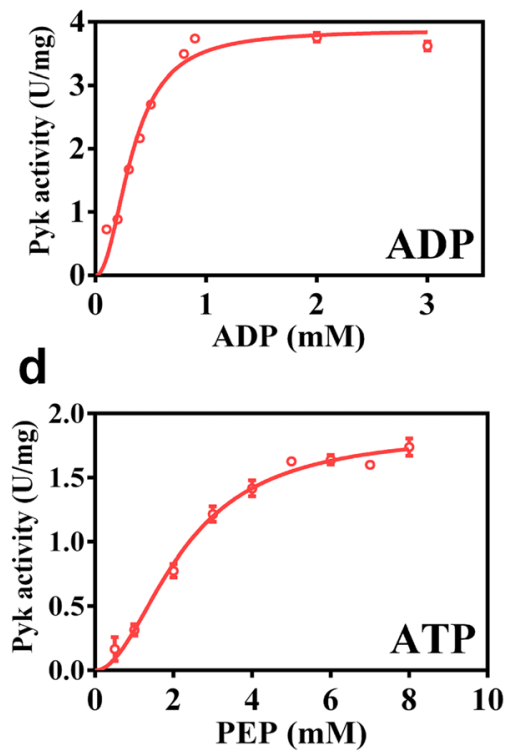
of Pyk2 with respect to PEP at a concentration of $5 \mathrm{mM}$ different effectors are shown. $\mathbf{c}$ FBP. $\mathbf{d}$ ATP. e CIT. The data points were fitted to the allosteric-sigmoidal equation using Prism software (GraphPad, USA). The $S_{0.5}$ (the substrate concentration giving one-half of the $V_{\text {max }}$ ) and $k_{\text {cat }}$ values were calculated. The experiments were performed at least in three times, and the error bars represent the standard error of the regression

that under aerobic conditions (Fig. 4b), which indicated that pyk2 was induced at the transcription level under oxygen deprivation. The mRNA level of $l d h A$ under oxygen deprivation was 2.61-fold higher than under aerobic conditions, which was consistent with the observed increase of $l d h A$ expression in the WT strain under low oxygen tension [21]. In contrast, the mRNA level of pyk1 under oxygen deprivation exhibited a 1.65-fold increase compared to the mRNA level obtained under aerobic conditions.

The Pyk activities in the WT, WT $\Delta p y k 1$, WT $\Delta p y k 2$ and WT $\Delta p y k 1 \Delta p y k 2$ strains were investigated under aerobic and oxygen-deprived conditions. The Pyk activity in the WT strain under oxygen-deprived conditions increased by $12 \%$ compared to the activity under aerobic conditions, which was mainly attributed to the increased expression of pyk2 (Table 1). The deficiency of pyk1 resulted in a 97\% decrease in Pyk activity; however, the Pyk activity in the WT $\Delta p y k 2$ strain was comparable to that in the WT strain under aerobic conditions. In addition, there was no significant difference in the specific glucose consumption rate and the specific growth rate of the WT $\Delta p y k 2$ strain compared with the WT strain (Additional file 1: Table S1), which indicated that the pyk2 gene might maintain a relatively low expression level under aerobic conditions. In contrast, pyk2 deficiency led to a $15 \%$ decrease in Pyk activity under oxygen-deprived conditions, and Pyk1 could only maintain $85 \%$ of Pyk activity in the WT $\Delta p y k 2$ strain compared to the WT strain. Therefore, these results illustrated that the expression of $p y k 2$ was induced and contributed to increased whole cell Pyk activity under oxygen deprivation.

\section{The effect of pyk1 or pyk2 expression on the production of lactic acid under oxygen deprivation}

Pyk2 had a slight effect on Pyk activity under aerobic conditions, and therefore, the role of Pyk2 was further investigated in the WT, WT $\Delta p y k 1, \mathrm{WT} \Delta p y k 2$ and 


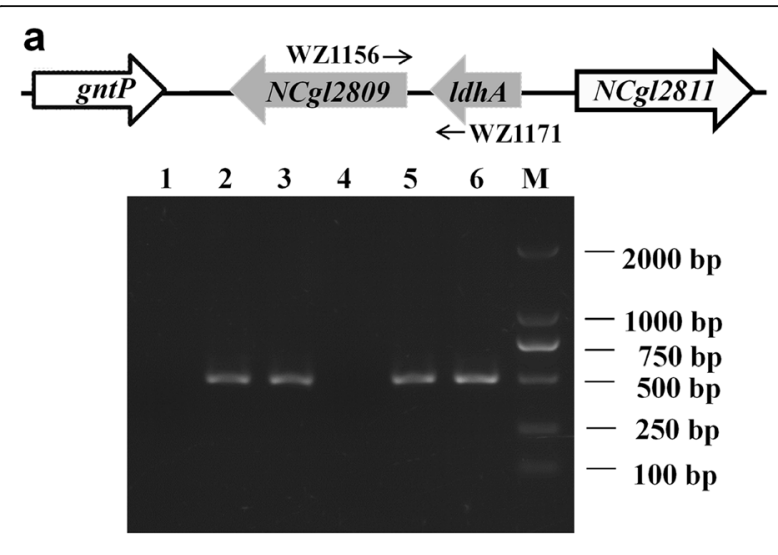

b

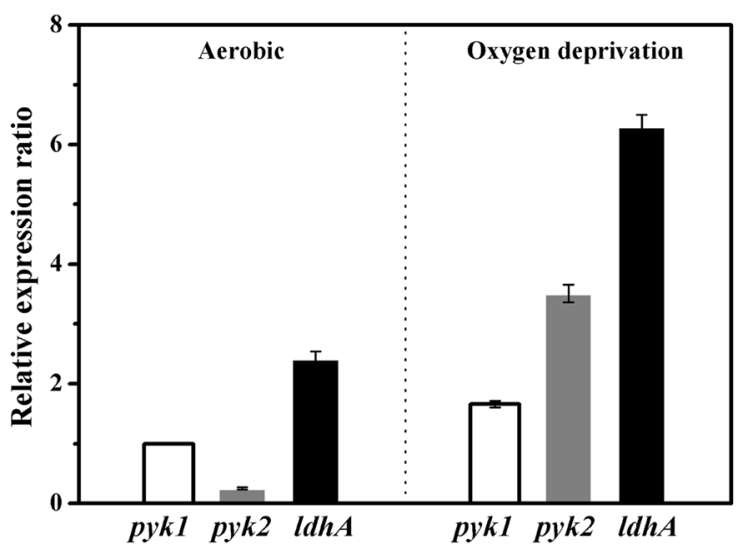

Fig. 4 Expression of the $I d h A$ and pyk2 genes in C. glutamicum. a Identification of the co-transcription of IdhA and pyk 2 in the IdhApyk2 cluster using RT-PCR. The C. glutamicum WT strain was cultured in minimal medium with glucose under aerobic conditions. The templates used for the PCR were as follows: lanes 1 and 4, total RNA reverse transcribed without reverse transcriptase; lanes 2 and 5, genomic DNA; and lanes 3 and 6, cDNA. The fragments in lanes 1,2 and 3 were amplified using the primers WZ1181/WZ868 for rpoB. In addition, the primers WZ1171 and WZ1156 were used for the IdhA-pyk2 region in lanes 4, 5 and 6 . $\mathbf{b}$ The relative transcription levels of the pyk1, pyk 2 and IdhA genes were analyzed by qRT-PCR. Total RNA was isolated from WT cells harvested at the exponential phase under aerobic conditions and at $3 \mathrm{~h}$ cultivation under oxygen-deprived conditions. The expression levels of pyk1, pyk 2 and IdhA under different conditions were compared against the expression of pyk1 under aerobic conditions (=1). The mean values from at least three independent cultures are shown with the standard deviations

WT $\Delta p y k 1 \Delta p y k 2$ strains under oxygen-deprived conditions. There was no obvious difference in the glucose consumption rate; however, a significant change was observed in the production of organic acids among these strains (Table 1). The yield of lactic acid from glucose in the pyk1- or $p y k 2$-deficient strains was similar, but there was a 13 and 7\% decrease in the production of lactic acid in the WT $\Delta p y k 1$ and WT $\Delta p y k 2$ strains, respectively, compared to the WT strain. The production of lactic acid in the double mutant decreased by $22 \%$, and the yield further decreased by $23 \%$. In contrast, the variation tendency of production of succinic acid was opposite to that of lactic acid. Compared to the WT strain, the production of succinic acid was 1.68 and 1.97-fold higher in the WT $\Delta p y k 2$ and WT $\Delta p y k 1$ strains, respectively. In addition, the titers of acetic acid were lower in the three mutants. These results indicated that $p y k 1$ or $p y k 2$ deficiency decreased the generation of lactic acid and increased the formation of succinic acid.

Pyk1 or pyk2 was overexpressed in the WT $\Delta p y k 1 \Delta$ pyk 2 and WT strains to determine their effects on the production of organic acids. Complementation of the WT $\Delta p y k 1 \Delta p y k 2$ strain with $p y k 1$ and $p y k 2$ resulted in a lactic acid production that was comparable to that of the WT strain (Table 1). Pyk activity was restored to a similar level as the WT strain. Furthermore, the titers of acetic acid in the three mutants were not significantly different from those of the WT strain. However, the overexpression of the pyk 1 or $p y k 2$ gene produced a 20 and $17 \%$ increase in the production of lactic acid in the WT strain, with 1.90 and 1.87-fold higher Pyk activities, respectively. In addition, the production of succinic acid was significantly decreased, and the production of acetic acid was increased in the mutants. Therefore, the overexpression of either $p y k 1$ or pyk 2 increased the production of lactic acid under oxygen deprivation.

\section{Fed-batch lactic acid production of the pyk2- overexpressing strain}

Because both $\mathrm{Mn}^{2+}$ and $\mathrm{K}^{+}$are necessary for Pyk2 activity, the effects of the concentrations of $\mathrm{MnSO}_{4}$ and $\mathrm{KCl}$ in the medium on the production of lactic acid were investigated in the WT $\Delta p y k 1 / \mathrm{pXMJ19-pyk2} \mathrm{strain} \mathrm{under}$ oxygen deprivation. The production of lactic acid was enhanced by increasing the concentration of $\mathrm{Mn}^{2+}$ and reached the highest level of $160.97 \pm 1.11 \mathrm{mM}$ with a yield of $82.95 \pm 0.91 \%$ at $1 \mathrm{~g} / \mathrm{L} \mathrm{MnSO}_{4}$ (Fig. 5a). The production of lactic acid was improved and then gradually decreased with increasing concentrations of $\mathrm{KCl}$ (Fig. 5a). The highest concentration of $158.38 \pm 3.57 \mathrm{mM}$ with a yield of $81.76 \pm 1.31 \%$ was obtained in the presence of $3 \mathrm{~g} / \mathrm{L} \mathrm{KCl}$. These results demonstrated that the activation of Pyk2 activity by $\mathrm{Mn}^{2+}$ and $\mathrm{K}^{+}$contributed to the increased production of lactic acid.

Fed-batch fermentation was performed in a $7.5 \mathrm{~L}$ fermenter to estimate the production of lactic acid at the optimal cation concentrations. The WT $\Delta p y k 1$ strain produced $454.04 \pm 5.55 \mathrm{mM}$ of lactic acid with the productivity of $18.86 \pm 0.21 \mathrm{mM} / \mathrm{h}$ (Fig. $5 \mathrm{~b}$ and Table 2). To determine the distribution of carbon flux towards organic acids, the yields were expressed as a percentage of the theoretical yield (100\% represented $2 \mathrm{~mol}$ of lactic acid, succinic acid or acetic acid per $1 \mathrm{~mol}$ of glucose consumed) [22, 23]. In the WT $\Delta p y k 1$ strain, $65.60 \pm 1.76 \%$ of the carbon flux was 
Table 1 The production of organic acids by C. glutamicum strains under oxygen deprivation ${ }^{\mathrm{a}}$

\begin{tabular}{|c|c|c|c|c|c|c|}
\hline Strains & $\begin{array}{l}\text { Glucose } \\
(\mathrm{mM} / \mathrm{h})\end{array}$ & $\begin{array}{l}\text { Lactic } \\
\text { acid }(\mathrm{mM})\end{array}$ & $\begin{array}{l}\text { Succinic } \\
\text { acid }(\mathrm{mM})\end{array}$ & $\begin{array}{l}\text { Acetic } \\
\text { acid (mM) }\end{array}$ & $\begin{array}{l}\text { Lactic acid } \\
\text { Yield }(\%)^{b}\end{array}$ & $\begin{array}{l}\text { Pyk activity } \\
(\mathrm{mU} / \mathrm{mg})^{c}\end{array}$ \\
\hline$\overline{\mathrm{WT}}$ & $28.46 \pm 0.56$ & $126.18 \pm 1.70$ & $22.59 \pm 1.65$ & $5.17 \pm 0.05$ & $73.90 \pm 0.99$ & $471.06 \pm 6.61(418.56 \pm 6.54)^{*}$ \\
\hline WT $\Delta p y k 1$ & $27.72 \pm 0.28$ & $109.90 \pm 4.00^{*}$ & $44.49 \pm 0.88^{*}$ & $5.89 \pm 0.91$ & $66.09 \pm 2.41^{*}$ & $69.98 \pm 5.00^{*}(11.34 \pm 0.42)^{*}$ \\
\hline WT $\Delta p y k 2$ & $29.75 \pm 0.11$ & $117.30 \pm 2.31^{*}$ & $38.02 \pm 0.82^{*}$ & $5.35 \pm 0.76$ & $65.71 \pm 1.29^{*}$ & $402.29 \pm 8.98^{*}(406.87 \pm 14.69)$ \\
\hline 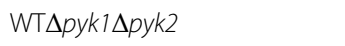 & $28.83 \pm 0.38$ & $98.80 \pm 1.11^{*}$ & $47.83 \pm 0.86^{*}$ & $6.06 \pm 0.64$ & $57.12 \pm 0.64^{*}$ & ND (ND) \\
\hline 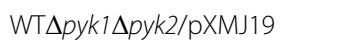 & $29.51 \pm 0.43$ & $99.17 \pm 2.31^{*}$ & $49.45 \pm 1.69^{*}$ & $4.40 \pm 1.80$ & $56.02 \pm 1.30^{*}$ & ND \\
\hline WT $\Delta p y k 1 \Delta p y k 2 / p X M J 19-p y k 1$ & $29.81 \pm 0.85$ & $127.29 \pm 3.57$ & $28.42 \pm 3.13^{*}$ & $6.30 \pm 2.19$ & $71.16 \pm 1.99$ & $472.94 \pm 21.29$ \\
\hline 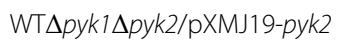 & $29.69 \pm 1.20$ & $128.77 \pm 2.22$ & $29.11 \pm 5.13^{*}$ & $6.23 \pm 2.07$ & $72.28 \pm 1.25$ & $442.72 \pm 10.64$ \\
\hline WT/pXMJ19 & $29.63 \pm 0.56$ & $125.44 \pm 4.00$ & $27.59 \pm 0.76^{*}$ & $6.72 \pm 1.16$ & $70.56 \pm 2.25$ & $486.38 \pm 31.68$ \\
\hline WT/pXMJ19-pyk1 & $32.78 \pm 0.74^{*}$ & $150.98 \pm 2.94^{*}$ & $13.37 \pm 0.14^{*}$ & $12.78 \pm 1.29^{*}$ & $76.77 \pm 1.49^{*}$ & $926.55 \pm 63.96^{*}$ \\
\hline WT/pXMJ19-pyk2 & $33.58 \pm 0.28^{*}$ & $146.17 \pm 3.20^{*}$ & $19.20 \pm 1.27^{*}$ & $15.38 \pm 0.89^{*}$ & $72.54 \pm 1.59$ & $911.45 \pm 31.86^{*}$ \\
\hline
\end{tabular}

${ }^{a}$ The cells were suspended to a final dry cell weight of $10 \mathrm{~g} / \mathrm{L}$ in $100 \mathrm{~mL}$ of CGXII medium with $100 \mathrm{mM}$ bicarbonate. The values were analyzed after $3 \mathrm{~h}$ under oxygen deprivation. The data were derived from experiments performed at least in three times, and the error bars represent the standard deviations

${ }^{b}$ The yields were calculated as a percentage of the theoretical yield (100\% represented 2 mol of lactic acid per 1 mol of glucose consumed)

${ }^{c}$ Pyk activities were measured under oxygen deprivation as described above. And the values in parentheses show the Pyk activities at the exponential growth phase under aerobic conditions. ND, not detected

${ }^{*}$,significant differences between WT and mutants under oxygen deprivation analyzed by $t$-test $(P<0.05)$ were marked. And the differences of Pyk activities of strains between aerobic and oxygen-deprived conditions are also shown $(P<0.05)$

directed to lactic acid, and $25.10 \pm 0.40 \%$ was directed to succinic acid. When the $p y k 2$ gene was overexpressed, the specific glucose uptake rate of the WT $\Delta p y k 1 / \mathrm{pXM} 19$ pyk 2 strain increased by $25 \%$, and the lactic acid production reached $669.03 \pm 15.59 \mathrm{mM}(60.27 \pm 1.40 \mathrm{~g} / \mathrm{L})$ (Fig. 5c and Table 2). The lactic acid production rate of the WT $\Delta p y k 1 / \mathrm{pXMJ19-pyk2}$ strain increased by $48 \%$ compared to the WT $\Delta p y k 1$ strain. Furthermore, $77.82 \pm 2.24 \%$ of the carbon flux was directed to lactic acid, and $10.57 \pm$ $0.24 \%$ was directed to succinic acid. Taken together, these results demonstrated that the overexpression of either $p y k 1$ or $p y k 2$ increased the carbon flux into lactic acid formation under oxygen deprivation.

\section{Discussion}

Pyk is an important control node in response to changes in glycolysis and energy charges. Two isoenzymes of Pyk have been found to be subjected to allosteric regulation by different effectors in $E$. coli and $S$. cerevisiae $[1,8]$. C. glutamicum was assumed to possess only one Pyk with higher activity compared to other bacterial Pyks $[14,16]$. In this study, Pyk2 was identified as a functional isoenzyme in C. glutamicum. Because Pyk2 was $\mathrm{Mn}^{2+}$ and $\mathrm{K}^{+}$ co-dependent, marginal Pyk 2 activity was detected in the pyk1-deficient mutant in the absence of the $\mathrm{K}^{+}$cation. This indicated that the binding of $\mathrm{K}^{+}$might induce the conversion of Pyk2 from the inactive conformation into the active conformation [24]. Our results confirmed that Pyk2 was activated by FBP despite the deficiency in the C-terminal domain containing the binding sites for the allosteric effector FBP in other Pyks [2, 25]. Consequently, we inferred that C. glutamicum Pyk2 might utilize a distinct allosteric mechanism that differed from other known FBP-activated Pyks. In C. glutamicum, the different allosteric activators of Pyk1 and Pyk2 made them subject to distinct metabolic regulation mechanisms similar to the regulation of the two isoenzymes in E. coli and $S$. cerevisiae $[1,8]$. Under oxygen deprivation, the restriction of glyceraldehyde-3-phosphate dehydrogenase (GAPDH), a glycolysis rate-limiting enzyme, might result in the accumulation of FBP [12], which activated Pyk2 to direct the metabolic flux of pyruvate towards the formation of lactic acid. The allosteric effect of Pyk2 resulted in a regulatory role in pyruvate metabolism under oxygen deprivation.

The $p y k 2$ and $l d h A$ in C. glutamicum were co-transcribed under aerobic conditions; therefore, $p y k 2$ followed the complicated regulatory mode of $l d h A$, which was subjected to dual repression under aerobic conditions mediated by the global regulator SugR and the special regulator LldR [17, 18]. SugR-mediated primary repression of $l d h A$ and $p y k 2$ transcription was relieved in the presence of sugar to induce lactic acid formation. In turn, the generated lactic acid alleviated the LldR-mediated repression to enhance the transcription of $l d h A$ and $p y k 2$ [26]. However, the mRNA level of $p y k 2$ was significantly higher than the mRNA level of ldhA under oxygen deprivation, which indicated that $p y k 2$ had a different transcription mode.

Under oxygen deprivation, C. glutamicum produces organic acids such as lactic acid, succinic acid and acetic acid from glucose with cell growth arrested [27]. The deletion or overexpression of two pyk genes had a significant influence on the production of organic acids. The deficiency of $p y k 2$ led to a decrease in the production of lactic acid and an increase in the synthesis of succinic acid. Moreover, the overexpression of $p y k 2$ promoted the formation of pyruvate and the production of lactic 

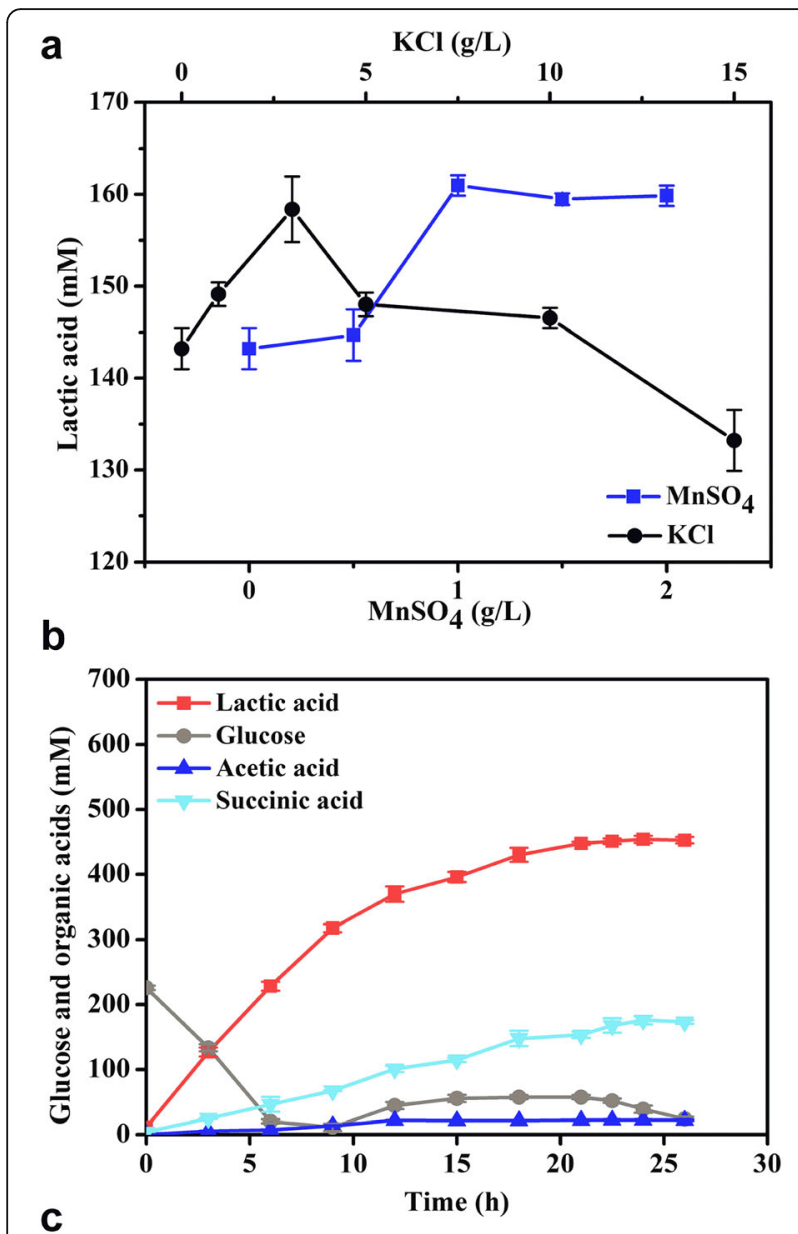

C

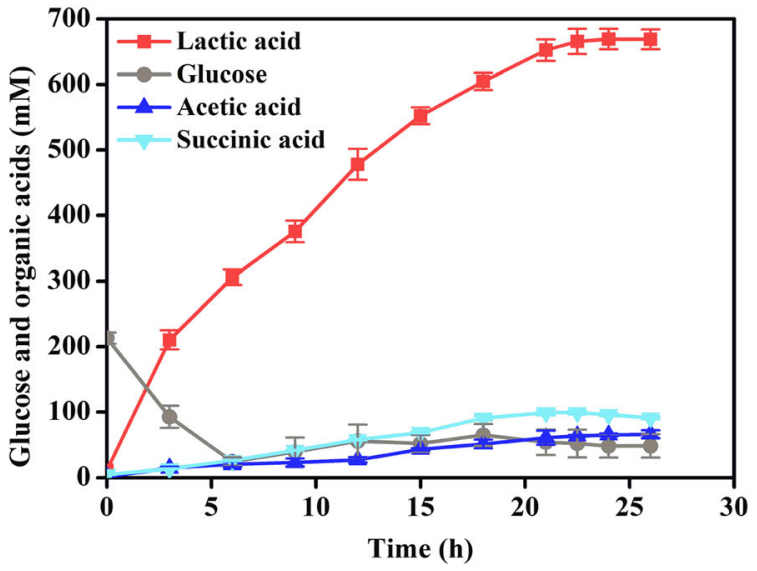

Fig. 5 Lactic acid production by C. glutamicum strains under oxygen deprivation. a The effects of $\mathrm{MnSO}_{4}$ and $\mathrm{KCl}$ on lactic acid production by the WT $\triangle p y k 1 / p X M J 19-p y k 2$ strain. The cells were suspended to a final dry cell weight of $10 \mathrm{~g} / \mathrm{L}$ in $100 \mathrm{~mL}$ of CGXII medium with $100 \mathrm{mM}$ bicarbonate. $\mathbf{b}$ Fed-batch production by the WTApyk1 strain under oxygen deprivation. c Fed-batch production by the WTApyk1/ pXMJ19-pyk2 strain under oxygen deprivation. For the fed-batch fermentation experiments, the cells were suspended to a final dry cell weight of $20 \mathrm{~g} / \mathrm{L}$ in $3 \mathrm{~L}$ of CGXII medium with $100 \mathrm{mM}$ bicarbonate. The data were derived from experiments performed at least in three times, and the error bars represent the standard deviations acid, whereas the metabolic flux from PEP towards oxaloacetate might decrease and led to decreased synthesis of succinic acid. Under oxygen deprivation, when the availability of pyruvate was decreased, the redundant PEP was redirected to synthesize succinic acid by PEP carboxylase, which was the predominant anaplerotic enzyme [10, 28, 29]. Our findings confirmed that $C$. glutamicum regulated the synthesis of lactic acid and succinic acid by Pyk and PEP carboxylase to maintain the intracellular $\mathrm{NADH} / \mathrm{NAD}^{+}$equilibrium under oxygen deprivation [27]. Therefore, our results suggested that Pyk is a key factor that influences the formation of lactic acid in C. glutamicum under oxygen deprivation.

Furthermore, Pyk2 homologs had been annotated in the genomes of Corynebacterium, Mycobacterium, Geobacillus, etc. The ldhA-pyk 2 cluster has been found in many representative Corynebacterium species (Additional file 1: Figure S3). A transcriptional unit composed of several genes encoding enzymes involved in the catalysis of related metabolic reactions has been proposed to be an effective means to rapidly adjust bacterial metabolism under different conditions [30, 31]. These results support the hypothesis that lactate dehydrogenase and Pyk 2 might be interdependent and play an important role in diverting the metabolic flux into lactic acid formation in C. glutamicum under low oxygen tensions. Therefore, the evolution of the $l d h A-p y k 2$ cluster for lactic acid synthesis grants $C$. glutamicum more metabolic flexibility in response to environmental changes.

\section{Conclusions}

In the present study, we identified that Pyk 2 is a novel pyruvate kinase in C. glutamicum and has significantly different biochemical properties than Pyk1. The catalytic activity of Pyk 2 was allosterically regulated by FBP activation. The allosteric behavior of Pyk made it an important switch point for the regulation of the glycolytic carbon flux distribution. Pyk2 and $l d h A$ were co-transcribed as a bicistronic mRNA under aerobic conditions. However, the mRNA level of $p y k 2$ in the WT strain was increased under oxygen deprivation and $p y k 1$ or $p y k 2$ deficiency decreased the production of lactic acid. The overexpression of either $p y k 1$ or pyk2 increased the activity of Pyk and the production of lactic acid. The fed-batch fermentation of the pyk2-overexpressing strain resulted in increased lactic acid production than the parent strain, which indicated that overexpression of Pyk redirected more carbon flux into lactic acid production under oxygen deprivation.

\section{Methods}

Bacterial strains, plasmids, and media

The strains and plasmids used in this study are listed in Table S3 (Additional file 1: Table S3). E. coli EC135 [32] and BL21 (DE3) (Novagen, Germany) were used for the gene cloning and the recombinant enzyme expression 
Table 2 The production of organic acids by C. glutamicum strains in fed-batch fermentation ${ }^{\mathrm{a}}$

\begin{tabular}{|c|c|c|c|c|c|c|c|}
\hline \multirow[t]{2}{*}{ Strains } & \multirow{2}{*}{$\begin{array}{l}\text { Glucose } \\
(\mathrm{mM} / \mathrm{h})\end{array}$} & \multirow{2}{*}{$\begin{array}{l}\text { Lactic acid } \\
(\mathrm{mM})\end{array}$} & \multirow{2}{*}{$\begin{array}{l}\text { Lactic acid productivity } \\
(\mathrm{mM} / \mathrm{h})\end{array}$} & \multicolumn{4}{|l|}{ Yield $(\%)$} \\
\hline & & & & Lactic acid & Succinic acid & Acetic acid & Total \\
\hline WT $\Delta p y k 1$ & $14.38 \pm 0.27$ & $454.04 \pm 5.55$ & $18.86 \pm 0.21$ & $65.60 \pm 1.76$ & $25.10 \pm 0.40$ & $3.20 \pm 0.18$ & $93.90 \pm 2.34$ \\
\hline WTApyk1/pXMJ19-pyk2 & $17.92 \pm 0.50$ & $669.03 \pm 15.59$ & $27.88 \pm 0.65$ & $77.82 \pm 2.24$ & $10.57 \pm 0.24$ & $7.70 \pm 0.68$ & $96.10 \pm 3.16$ \\
\hline
\end{tabular}

${ }^{a}$ The cells were suspended to a final dry cell weight of $20 \mathrm{~g} / \mathrm{L}$ in $3 \mathrm{~L}$ of CGXII medium with 100 mM bicarbonate. The data were derived from experiments performed at least in three times, and the error bars represent the standard deviations

${ }^{\mathrm{b}}$ The yields were calculated as a percentage of the theoretical yield (100\% represented 2 mol of lactic acid, succinic acid or acetic acid per 1 mol of glucose consumed)

experiments, respectively. The E. coli strains were aerobically grown at $37^{\circ} \mathrm{C}$ in Luria-Bertani medium [33]. The $C$. glutamicum wild-type strain ATCC 13032 (WT) was routinely cultivated in brain heart infusion (BHI) medium (37 $\mathrm{g} / \mathrm{L}$ brain heart infusion with $91 \mathrm{~g} / \mathrm{L}$ sorbitol) at $30^{\circ} \mathrm{C}$ for the genetic disruption and complementation experiments [9]. The antibiotic concentrations were $50 \mu \mathrm{g} / \mathrm{mL}$ kanamycin and $20 \mu \mathrm{g} / \mathrm{mL}$ chloramphenicol for E. coli, and $25 \mu \mathrm{g} / \mathrm{mL}$ kanamycin and $10 \mu \mathrm{g} / \mathrm{mL}$ chloramphenicol for C. glutamicum.

\section{Culture conditions}

For the aerobic growth experiments, pre-cultures inoculated from agar plates were aerobically grown in $50 \mathrm{~mL}$ of CGIII medium with $4 \%$ glucose in $500 \mathrm{~mL}$ shake flasks on a shaker at $220 \mathrm{rpm}$ for $12 \mathrm{~h}$ [34]. After washing the cells with CGXII minimal medium without carbon and nitrogen sources, the C. glutamicum strains were inoculated in $50 \mathrm{~mL}$ of CGXII minimal medium in $500 \mathrm{~mL}$ shake flasks with an initial optical density of $600 \mathrm{~nm}$ of approximately 1.5 (dry cell weight of $0.45 \mathrm{~g} / \mathrm{L}$ ) and incubated at $220 \mathrm{rpm}$ [35]. A total of $100 \mathrm{mM}$ glucose or $100 \mathrm{mM} \mathrm{D-}$ ribose was added as the carbon sources. The growth of the strains was assessed by measuring the $\mathrm{OD}_{600}$. When necessary, $0.5 \mathrm{mM}$ isopropylthio- $\beta$-D-galactopyranoside (IPTG) was supplemented after inoculation.

For the oxygen-deprived growth experiments, the $C$. glutamicum strains were pre-cultured as described above for the aerobic growth experiments [34]. The cell suspension was harvested by centrifugation at $8000 \times g$ and $4^{\circ} \mathrm{C}$ and washed with a CGXII minimal medium without carbon and nitrogen sources. The washed cells were suspended to a final dry cell weight of $10 \mathrm{~g} / \mathrm{L}$ in $100 \mathrm{~mL}$ of CGXII minimal medium with $100 \mathrm{mM}$ bicarbonate in $150 \mathrm{~mL}$ lidded bottles and incubated by preventing aeration and gentle agitation [10]. Oxygen deprivation was obtained using $\mathrm{N}_{2}$ flux. The $\mathrm{pH}$ was maintained at $\mathrm{pH} 7.0$ by adding ammonia. Under oxygen deprivation, the growth of C. glutamicum was arrested. The effects of $\mathrm{Mn}^{2+}$ or $\mathrm{K}^{+}$on fermentation were studied using $\mathrm{MnSO}_{4}(0-2 \mathrm{~g} / \mathrm{L})$ or $\mathrm{KCl}$ (0-15 g/L) supplementation. For the fed-batch fermentation experiments, pre-cultures inoculated from agar plates were aerobically grown in $1 \mathrm{~L}$ shake flasks on a shaker at $220 \mathrm{rpm}$ for $12 \mathrm{~h}$. Afterward, the cells were harvested by centrifugation at $8000 \times g$ and $4^{\circ} \mathrm{C}$, and washed with CGXII minimal medium without carbon and nitrogen sources. The washed cells were resuspended at a final dry cell weight of $20 \mathrm{~g} / \mathrm{L}$ in $3 \mathrm{~L}$ of CGXII minimal medium with $100 \mathrm{mM}$ bicarbonate and $222 \mathrm{mM}$ glucose in a $7.5 \mathrm{~L}$ fermenter (New Brunswick BioFlo 115, Germany). $\mathrm{N}_{2}$ flux was flushed to maintain oxygen deprivation. When needed, $50 \%$ glucose was continuously fed to maintain the residue glucose between 0 and $50 \mathrm{mM}$. The strains were incubated at $30^{\circ} \mathrm{C}$ and $200 \mathrm{rpm}$, and the $\mathrm{pH}$ was maintained at 7.0 using a $\mathrm{pH}$ controller with automatic addition of an ammonia solution.

\section{Construction of plasmids and strains}

Total genomic DNA of the WT strain was extracted according to previously described methods [36]. The oligonucleotides used in this study are shown in Table S4 (Additional file 1: Table S4). For the gene disruption experiments, the upstream and downstream homologous fragments were amplified using PCR with the primers WZ539/WZ540 and WZ541/WZ542 for the pyk1 gene, and WZ545/WZ546 and WZ547/WZ548 for the pyk2 gene. The amplified DNA fragments were spliced using overlap extension PCR and ligated into the suicide vector pK18mobsacB [37]. The plasmids were verified by DNA sequencing and then transformed into the WT strain through electroporation to generate the WT $\Delta p y k 1$ strain, which was further verified by sequencing. Similarly, the pyk2 gene was disrupted in the WT and WT $\Delta p y k 1$ strains. The C. glutamicum and E. coli shuttle vector pXMJ19 was used for the gene overexpression studies. The replication origin of this vector was derived from that of pBL1 with a cryptic low copy number [38]. For the gene complementation experiments, the C. glutamicum strain was transformed by the plasmid pXMJ19, which contained the intact $p y k 1$ and $p y k 2$ genes. To induce the expression of the $p y k 1$ and $p y k 2$ genes, $0.5 \mathrm{mM}$ IPTG was supplemented.

\section{Expression and purification of Pyk2}

The pyk2 gene was cloned into the vector pET-28a and expressed in the BL21 (DE3) strain. When the $\mathrm{OD}_{600}$ reached 0.6, the cells were induced with $0.1 \mathrm{mM}$ IPTG at $16^{\circ} \mathrm{C}$ and harvested by centrifugation after the $\mathrm{OD}_{600}$ reaching 4.0. The cells were resuspended in buffer $(20 \mathrm{mM}$ Tris- 
$\mathrm{HCl}$ (pH 7.5), $150 \mathrm{mM} \mathrm{NaCl}$, and $10 \%$ glycerol) and then disrupted by sonication. The supernatants were collected by centrifugation at $12,000 \times g$ for $30 \mathrm{~min}$ at $4^{\circ} \mathrm{C}$. The recombinant $\mathrm{Pyk} 2$ was purified using $\mathrm{Ni}^{2+}$-affinity chromatography (GE Healthcare, USA). The eluted protein solutions were concentrated by ultrafiltration (Merck Millipore, Germany). Subsequently, the protein solution was applied to a Resource Q column (GE Healthcare, USA), which was equilibrated with a standard buffer $(20 \mathrm{mM}$ Tris$\mathrm{HCl}$ ( $\mathrm{pH}$ 7.5), $1 \mathrm{M} \mathrm{NaCl}$, and $10 \%$ glycerol). The fraction was pooled and concentrated for further analysis. The eluted protein solution was incubated with thrombin (Merck Millipore, Germany) in $1 \times \mathrm{PBS}\left(\mathrm{pH} 7.3\right.$ ) at $22{ }^{\circ} \mathrm{C}$ for $16 \mathrm{~h}$, which efficiently cleaved the $\mathrm{N}$-terminal His-tag. After the cleavage reaction, the reaction mixture was eluted through a $\mathrm{Ni}^{2+}$-affinity column to remove the Histagged thrombin. The molecular mass of Pyk2 was analyzed using gel filtration chromatography on a Superdex 200 10/300 GL column (GE Healthcare, USA), which was equilibrated with $50 \mathrm{mM}$ potassium phosphate buffer (pH 7.0) containing $150 \mathrm{mM} \mathrm{NaCl}$. A standard curve was determined based on the elution volumes of the protein standards (GE Healthcare, USA). The purity of the purified Pyk2 was determined by SDS-PAGE. The protein concentrations were determined by the Bradford method using the Bio-Rad Protein Assay Reagent (Bio-Rad, USA).

\section{Enzymatic activity and property determination}

The assay for Pyk activity was based on changes in the absorbance of NADH at $340 \mathrm{~nm}$ coupled with the L-lactate dehydrogenase [39]. The reaction mixture contained $100 \mathrm{mM}$ Tris- $\mathrm{HCl}\left(\mathrm{pH}\right.$ 7.4), $5 \mathrm{mM} \mathrm{MnSO} \mathrm{M}_{4} \cdot \mathrm{H}_{2} \mathrm{O}, 5 \mathrm{mM}$ PEP, $2 \mathrm{mM}$ ADP, $100 \mathrm{mM} \mathrm{KCl}, 0.2 \mathrm{mM} \mathrm{NADH}, 6$ units L-lactate dehydrogenase, and the enzyme in a total volume of $0.5 \mathrm{~mL}$. To avoid a decrease in L-lactate dehydrogenase activity at extreme conditions ( $\mathrm{pH}$ and temperature), the amount of L-lactate dehydrogenase was increased to 15 units. The reaction was initiated by the addition of PEP, and the decrease in the absorbance at $340 \mathrm{~nm}$ was monitored by a UV-visible spectrophotometer (Unico, USA). One unit of activity was defined as the amount of enzyme that converted $1 \mu \mathrm{mol}$ of PEP to pyruvate per min at $25^{\circ} \mathrm{C}$. To determine the effect of the $\mathrm{pH}$ on the enzyme activity, various buffer systems ( $\mathrm{pH}$ 5.0-9.5) were used at $100 \mathrm{mM}$. The optimum temperature of Pyk2 was determined at temperatures ranging from 20 to $70^{\circ} \mathrm{C}$. To exclude PEP hydrolysis with increasing temperatures, the relative Pyk2 activity was calculated by subtracting the background. The effects of different cations on Pyk activity were assayed by replacing $\mathrm{Mn}^{2+}$ with $5 \mathrm{mM}$ or $10 \mathrm{mM}$ of other cations $\left(\mathrm{Mg}^{2+}, \mathrm{Cu}^{2+}\right.$, $\mathrm{Co}^{2+}, \mathrm{Ca}^{2+}, \mathrm{Ni}^{2+}, \mathrm{Zn}^{2+}, \mathrm{Ba}^{2+}, \mathrm{Fe}^{2+}, \mathrm{Fe}^{3+}$ or $\mathrm{Al}^{3+}$ ) or replacing $\mathrm{K}^{+}$with $50 \mathrm{mM}$ or $100 \mathrm{mM}$ of monovalent cations $\left(\mathrm{NH}_{4}^{+}, \mathrm{Li}^{+}\right.$, or $\left.\mathrm{Na}^{+}\right)$. The enzyme activity was also measured without any cations. The data were obtained from three independent experiments.

\section{Analysis of kinetic properties}

The enzymatic activities were assayed using various concentrations of PEP and ADP under conditions identical to those described above. To determine the kinetics, the PEP concentration was varied with the concentration of $\mathrm{ADP}$ at $2 \mathrm{mM}$, or the ADP concentration was varied with the concentration of PEP at $5 \mathrm{mM}$. The effects of the various effectors tested on PEP were assessed with $2 \mathrm{mM}$ ADP. The formation of the product was linear throughout the period. The data were fitted to an allosteric sigmoidal kinetic model using Prism software (GraphPad, USA). The $S_{0.5}$ (the substrate concentration giving one-half of $V_{\max }$ ) and $n_{\mathrm{H}}$ (Hill coefficient) values were calculated. The $k_{\text {cat }}$ value was calculated according to the $V_{\max }$ and the subunit molecular weight of $67,572 \mathrm{Da}$. All data were obtained from at least three independent experiments.

\section{Analytical methods}

Glucose was measured with an enzyme electrode glucose sensor (SBA-40D, Shandong Province Academy of Sciences, China). The dry cell weights of the C. glutamicum strains were calculated as one optical density unit at $600 \mathrm{~nm}$ to $0.3 \mathrm{~g}$ dry cell weight/L [40]. The specific growth rate $\mu(1 / \mathrm{h})$ was estimated using a linear regression. The biomass yield $\left(\mathrm{Y}_{\mathrm{X} / \mathrm{S}}\right)$ was deduced from the individual biomass and glucose balancing, and the specific glucose uptake rate $\left(\mathrm{q}_{\mathrm{S}}\right)$ was calculated from the specific growth rate and the biomass yield [41]. Organic acids were determined by high performance liquid chromatography equipped with an SB-Aq column $(4.6 \times 250 \mathrm{~mm}$; Agilent Technologies, USA) at $210 \mathrm{~nm}$. Mobile phase A (20 mM KH${ }_{2} \mathrm{PO}_{4}$, $\mathrm{pH}$ 2.3) and mobile phase $\mathrm{B}$ (acetonitrile) were at a ratio of 95:5 [42]. To measure the enzyme activity, the cells were resuspended in the indicated buffer $(100 \mathrm{mM}$ Tris$\mathrm{HCl} \mathrm{pH} 7.5$ and $10 \%$ glycerol) and disrupted by ultrasonic treatment at $4{ }^{\circ} \mathrm{C}$. The enzyme activity was monitored by measuring the changes in the NADH concentration at $340 \mathrm{~nm}$. For Pyk, the reaction mixture was used as described above with $5 \mathrm{mM}$ FBP. The Student's $t$-test was performed with SPSS software to determine whether the difference was statistically significant.

\section{RNA preparation and RT-PCR analysis}

Total RNA was isolated from the cells with the RNAprep Pure Cell/Bacteria Kit (Tiangen, China). The cDNA from approximately $300 \mathrm{ng}$ of RNA was prepared using the specific primers listed in Table S4 (Additional file 1: Table S4) and the FastQuant RT Kit (Tiangen, China). The rpoB gene, which encodes RNA polymerase $\beta$ subunit, was used as the reference gene [43]. The primer pair WZ1171 and WZ1156 was used to amplify the ldhA-pyk2 region in the 
RT-PCR. Genomic DNA was used as a positive control in the PCR reactions. RNA reverse transcribed without reverse transcriptase was used as a negative control to exclude DNA contaminants in the RNA preparation.

The qRT-PCR (quantitative reverse transcription-PCR) was performed with the GoTaq qPCR master mix (Promega, USA) in a $20 \mu \mathrm{L}$ mixture using the LightCycler 96 Real-Time PCR System (Roche, Switzerland). The data analysis was performed using the LightCycler 96 software (Roche, Switzerland).

\section{Sequence alignment}

Database searches and sequence comparisons were performed with the BLAST programs at the BLAST tool on the National Center for Biotechnology Information website (https://blast.ncbi.nlm.nih.gov/Blast.cgi). Multiple sequence alignments were generated with the CLUSTAL $\mathrm{X}$ program [44]. Alignment of the secondary structures was produced using the high resolution X-ray crystallographic structure of E. coli PykF (PDB code 1PKY) as the template and ESPript 3.0 (http://espript.ibcp.fr/ESPript/ ESPript/) with default settings.

\section{Additional file}

Additional file 1: Table S1. Growth kinetics of the pyk mutants on glucose under aerobic conditions. Table S2. Kinetic parameters of the Pyk2 for substrates. Table S3. Strains and plasmids used in this study. Table S4. Primers used in this study. Figure S1. The map positions of the pyk genes and the multiple alignment of the Pyk sequences. Figure S2. Kinetic parameters of Pyk2 with respect to PEP at a concentration of $5 \mathrm{mM}$ G6P (a) or AMP (b). Figure S3. Conservation of pyk2 gene and adjacent genes in species of the Corynebacterium and other species. (DOCX $651 \mathrm{~kb}$ )

\section{Abbreviations \\ BHI: Brain heart infusion; CIT: Citrate; FBP: Fructose 1,6-bisphosphate; G6P: Glucose- 6-phosphate; GAPDH: Glyceraldehyde-3-phosphate dehydrogenase; IPTG: Isopropylthio- $\beta$-D-galactopyranoside; IdhA: L-lactate dehydrogenase encoding gene; PEP: Phosphoenolpyruvate; PTS: Phosphotransferase transport system; Pyk: Pyruvate kinase; qRT-PCR: quantitative reverse transcription-PCR; rpoB: RNA polymerase $\beta$ subunit encoding gene; SugR: DeoR-type transcriptional regulator; WT: Wild-type}

\section{Acknowledgments}

We thank Dr. Aihua Deng and Qian Liu for assistance with critical reading of the manuscript.

\section{Funding}

This work was supported by grants from National Hi-Tech Research and Development Program of China (2014AA021203), the Science and Technology Service Network Initiative of the Chinese Academy of Sciences (KFJ-EW-STS078), National Natural Science Foundation of China (31100074) and the Ministry of Science and Technology of China (2008BAl63B01 and 2008ZX09401-05).

\section{Availability of data and materials}

The supporting materials of this article are included in the article.

\section{Authors' contributions}

TW, $Y Z$ and $X C$ designed the project. $X C, X S$ and $Y Z$ performed experiments. $X C, S L, Y L$ and $Y Z$ analyzed the data. $X C, X S, Y Z$ and TW mainly wrote the manuscript. All authors read and approved the final manuscript.

\section{Competing interests}

The authors declare that they have no competing interests.

\section{Consent for publication}

Not applicable.

Ethics approval and consent to participate

Not applicable.

\section{Author details}

${ }^{1}$ CAS Key Laboratory of Pathogenic Microbiology and Immunology, Institute of Microbiology, Chinese Academy of Sciences, Beijing 100101, People's Republic of China. ${ }^{2}$ University of Chinese Academy of Sciences, Beijing 100049, People's Republic of China. ${ }^{3}$ Savaid Medical School, University of Chinese Academy of Sciences, Beijing 100049, People's Republic of China.

Received: 22 June 2016 Accepted: 1 November 2016

Published online: 16 November 2016

\section{References}

1. Muñoz ME, Ponce E. Pyruvate kinase: current status of regulatory and functional properties. Comp Biochem Physiol B Biochem Mol Biol. 2003;135:197-218

2. Mattevi A, Valentini G, Rizzi M, Speranza ML, Bolognesi M, Coda A. Crystal structure of Escherichia coli pyruvate kinase type I: molecular basis of the allosteric transition. Structure. 1995;3:729-41.

3. Steiner P, Fussenegger M, Bailey JE, Sauer U. Cloning and expression of the Zymomonas mobilis pyruvate kinase gene in Escherichia coli. Gene. 1998:220:31-8.

4. Mattevi A, Bolognesi M, Valentini G. The allosteric regulation of pyruvate kinase. FEBS Lett. 1996:389:15-9.

5. Ponce E. Effect of growth rate reduction and genetic modifications on acetate accumulation and biomass yields in Escherichia coli. J Biosci Bioeng. 1999;87:775-80.

6. Al Zaid Siddiquee K, Arauzo-Bravo MJ, Shimizu K. Effect of a pyruvate kinase (pykf-gene) knockout mutation on the control of gene expression and metabolic fluxes in Escherichia coli. FEMS Microbiol Lett. 2004;235:25-33.

7. Ponce E, Martínez A, Bolívar F, Valle F. Stimulation of glucose catabolism through the pentose pathway by the absence of the two pyruvate kinase isoenzymes in Escherichia coli. Biotechnol Bioeng. 1998;58:292-5.

8. Boles E, Schulte F, Miosga T, Freidel K, Schlüter E, Zimmermann FK, Hollenberg CP, Heinisch JJ. Characterization of a glucose-repressed pyruvate kinase (Pyk2p) in Saccharomyces cerevisiae that is catalytically insensitive to fructose-1,6-bisphosphate. J Bacteriol. 1997;179:2987-93.

9. Kalinowski J, Bathe B, Bartels D, Bischoff N, Bott M, Burkovski A, Dusch N, Eggeling L, Eikmanns BJ, Gaigalat L, Goesmann A, Hartmann M, Huthmacher K, Krämer R, Linke B, McHardy AC, Meyer F, Möckel B, Pfefferle W, Pühler A, Rey DA, Rückert C, Rupp O, Sahm H, Wendisch VF, Wiegräbe I, Tauch A. The complete Corynebacterium glutamicum ATCC 13032 genome sequence and its impact on the production of L-aspartate-derived amino acids and vitamins. J Biotechnol. 2003;104:5-25.

10. Okino $\mathrm{S}$, Inui M, Yukawa H. Production of organic acids by Corynebacterium glutamicum under oxygen deprivation. Appl Microbiol Biotechnol. 2005;68:475-80.

11. Jojima T, Fujii M, Mori E, Inui M, Yukawa H. Engineering of sugar metabolism of Corynebacterium glutamicum for production of amino acid L-alanine under oxygen deprivation. Appl Microbiol Biotechnol. 2010;87:159-65.

12. Yamamoto S, Gunji W, Suzuki H, Toda H, Suda M, Jojima T, Inui M, Yukawa $\mathrm{H}$. Overexpression of genes encoding glycolytic enzymes in Corynebacterium glutamicum enhances glucose metabolism and alanine production under oxygen deprivation conditions. Appl Environ Microbiol. 2012;78:4447-57.

13. Hasegawa S, Suda M, Uematsu K, Natsuma Y, Hiraga K, Jojima T, Inui M, Yukawa $\mathrm{H}$. Engineering of Corynebacterium glutamicum for high-yield Lvaline production under oxygen deprivation conditions. Appl Environ Microbiol. 2013;79:1250-7.

14. Sawada K, Zen-in S, Wada M, Yokota A. Metabolic changes in a pyruvate kinase gene deletion mutant of Corynebacterium glutamicum ATCC 13032. Metab Eng. 2010;12:401-7.

15. Netzer R, Krause M, Rittmann D, Peters-Wendisch PG, Eggeling L, Wendisch VF, Sahm H. Roles of pyruvate kinase and malic enzyme in Corynebacterium 
glutamicum for growth on carbon sources requiring gluconeogenesis. Arch Microbiol. 2004;182:354-63.

16. Jetten MSM, Gubler ME, Lee SH, Sinskey AJ. Structural and functional analysis of pyruvate kinase from Corynebacterium glutamicum. Appl Environ Microbiol. 1994;60:2501-7.

17. Engels V, Lindner SN, Wendisch VF. The global repressor SugR controls expression of genes of glycolysis and of the L-lactate dehydrogenase LdhA in Corynebacterium glutamicum. J Bacteriol. 2008;190:8033-44.

18. Toyoda K, Teramoto H, Inui M, Yukawa H. Molecular mechanism of SugRmediated sugar-dependent expression of the IdhA gene encoding L-lactate dehydrogenase in Corynebacterium glutamicum. Appl Microbiol Biotechnol. 2009;83:315-27.

19. Becker J, Klopprogge C, Wittmann C. Metabolic responses to pyruvate kinase deletion in lysine producing Corynebacterium glutamicum. Microb Cell Fact. 2008:7:8.

20. Nentwich SS, Brinkrolf K, Gaigalat L, Hüser AT, Rey DA, Mohrbach T, Marin K, Pühler A, Tauch A, Kalinowski J. Characterization of the Lacl-type transcriptional repressor RbsR controlling ribose transport in Corynebacterium glutamicum ATCC 13032. Microbiology. 2009;155:150-64.

21. Inui M, Suda M, Okino S, Nonaka H, Puskás LG, Vertès AA, Yukawa H. Transcriptional profiling of Corynebacterium glutamicum metabolism during organic acid production under oxygen deprivation conditions. Microbiology. 2007;153:2491-504

22. Guillouet S, Rodal AA, An G-H, Lessard PA, Sinskey AJ. Expression of the Escherichia coli catabolic threonine dehydratase in Corynebacterium glutamicum and its effect on isoleucine production. Appl Environ Microbiol. 1999;65:3100-7.

23. Hasegawa S, Uematsu K, Natsuma Y, Suda M, Hiraga K, Jojima T, Inui M, Yukawa $\mathrm{H}$. Improvement of the redox balance increases L-valine production by Corynebacterium glutamicum under oxygen deprivation conditions. Appl Environ Microbiol. 2012;78:865-75.

24. Oria-Hernández J, Riveros-Rosas H, Ramírez-Sílva L. Dichotomic phylogenetic tree of the pyruvate kinase family: $\mathrm{K}^{+}$-dependent and -independent enzymes. J Biol Chem. 2006;281:30717-24.

25. Jurica MS, Mesecar A, Heath PJ, Shi W, Nowak T, Stoddard BL. The allosteric regulation of pyruvate kinase by fructose-1,6-bisphosphate. Structure. 1998; 6:195-210.

26. Georgi T, Engels V, Wendisch VF. Regulation of L-lactate utilization by the FadR-type regulator LIdR of Corynebacterium glutamicum. J Bacteriol. 2008; 190:963-71.

27. Inui M, Murakami S, Okino S, Kawaguchi H, Vertès AA, Yukawa H. Metabolic analysis of Corynebacterium glutamicum during lactate and succinate productions under oxygen deprivation conditions. J Mol Microbio Biotechnol. 2004;7:182-96.

28. Okino S, Noburyu R, Suda M, Jojima T, Inui M, Yukawa H. An efficient succinic acid production process in a metabolically engineered Corynebacterium glutamicum strain. Appl Microbiol Biotechnol. 2008;81:459-64.

29. Dietrich C, Nato A, Bost B, Le Marechal P, Guyonvarch A. Regulation of Idh expression during biotin-limited growth of Corynebacterium glutamicum. Microbiology. 2009;155:1360-75.

30. Han SO, Inui M, Yukawa H. Expression of Corynebacterium glutamicum glycolytic genes varies with carbon source and growth phase. Microbiology. 2007;153:2190-202.

31. Llanos RM, Harris CJ, Hillier AJ, Davidson BE. Identification of a novel operon in Lactococcus lactis encoding three enzymes for lactic acid synthesis: phosphofructokinase, pyruvate kinase, and lactate dehydrogenase. J Bacteriol. 1993;175:2541-51.

32. Zhang G, Wang W, Deng A, Sun Z, Zhang Y, Liang Y, Che Y, Wen T. A mimicking-of-DNA-methylation-patterns pipeline for overcoming the restriction barrier of bacteria. PLoS Genet. 2012;8:e1002987.

33. Sezonov G, Joseleau-Petit D, D'Ari R. Escherichia coli physiology in LuriaBertani broth. J Bacteriol. 2007;189:8746-9.

34. Menkel E, Thierbach G, Eggeling L, Sahm H. Influence of increased aspartate availability on lysine formation by a recombinant strain of Corynebacterium glutamicum and utilization of fumarate. Appl Environ Microbiol. 1989:55:684-8.

35. Gaigalat L, Schlüter JP, Hartmann M, Mormann S, Tauch A, Pühler A, Kalinowski J. The DeoR-type transcriptional regulator SugR acts as a repressor for genes encoding the phosphoenolpyruvate:sugar phosphotransferase system (PTS) in Corynebacterium glutamicum. BMC Mol Biol. 2007;8:104
36. Zhang Y, Shang X, Lai S, Zhang G, Liang Y, Wen T. Development and application of an arabinose-inducible expression system by facilitating inducer uptake in Corynebacterium glutamicum. Appl Environ Microbiol. 2012:78:5831-8.

37. Schäfer A, Tauch A, Jäger W, Kalinowski J, Thierbach G, Pühler A. Small mobilizable multipurpose cloning vectors derived from the Escherichia coli plasmids pK18 and pK19: selection of defined deletions in the chromosome of Corynebacterium glutamicum. Gene. 1994;145:69-73.

38. Jakoby M, Ngouoto-Nkili C-E, Burkovski A. Construction and application of new Corynebacterium glutamicum vectors. Biotechnol Tech. 1999;13:437-41.

39. Gubler M, Jetten M, Lee SH, Sinskey AJ. Cloning of the pyruvate kinase gene (pyk) of Corynebacterium glutamicum and site-specific inactivation of pyk in a lysine-producing Corynebacterium lactofermentum strain. Appl Environ Microbiol. 1994;60:2494-500

40. Buchholz J, Schwentner A, Brunnenkan B, Gabris C, Grimm S, Gerstmeir R, Takors R, Eikmanns BJ, Blombach B. Platform engineering of Corynebacterium glutamicum with reduced pyruvate dehydrogenase complex activity for improved production of L-lysine, L-valine, and 2ketoisovalerate. Appl Environ Microbiol. 2013;79:5566-75.

41. Blombach B, Buchholz J, Busche T, Kalinowski J, Takors R. Impact of different $\mathrm{CO}_{2} / \mathrm{HCO}_{3}^{-}$levels on metabolism and regulation in Corynebacterium glutamicum. J Biotechnol. 2013;168:331-40.

42. Lai SJ, Zhang Y, Liu SW, Liang Y, Shang XL, Chai X, Wen TY. Metabolic engineering and flux analysis of Corynebacterium glutamicum for L-serine production. Sci China Life Sci. 2012;55:283-90.

43. Shang X, Zhang Y, Zhang G, Chai X, Deng A, Liang Y, Wen T. Characterization and molecular mechanism of AroP as an aromatic amino acid and histidine transporter in Corynebacterium glutamicum. J Bacteriol. 2013;195:5334-42.

44. Jeanmougin F, Thompson JD, Gouy M, Higgins DG, Gibson TJ. Multiple sequence alignment with Clustal X. Trends Biochem Sci. 1998;23:403-5.

\section{Submit your next manuscript to BioMed Central and we will help you at every step:}

- We accept pre-submission inquiries

- Our selector tool helps you to find the most relevant journal

- We provide round the clock customer support

- Convenient online submission

- Thorough peer review

- Inclusion in PubMed and all major indexing services

- Maximum visibility for your research

Submit your manuscript at www.biomedcentral.com/submit

) BioMed Central 